\title{
Room Temperature Ionic Liquid as Electrolyte for Lithium Ion Battery
}

\author{
Y.S. Fung $^{1 *}$ and Y. Yang ${ }^{2}$ \\ *Corresponding author: ysfung@hkucc.hku.hk \\ ${ }^{1}$ Department of Chemistry, The University of Hong Kong, Pokfulam Road, Hong Kong SAR, PR China \\ ${ }^{2}$ State Key Laboratory for Physical Chemistry of Solid Surfaces, and Department of Chemistry, College \\ of Chemistry and Chemical Engineering, Xiamen University, Xiamen 361005, PR China
}

Pure N-methyl-N-butylpyrrolidinium bis(trifluoromethylsulfonyl)imide (Py ${ }_{14}$ TFSI) Ionic Liquid has been reported to have a good room temperature ionic conductivity of higher than $1 \mathrm{mS} \cdot \mathrm{cm}^{-1}$ and an overall stability window in excess of 5.5V [1]. Py ${ }_{14}$ TFSI with lithium salt (e.g. LiTFSI or LiPF ) thus provides a promising electrolyte for lithium ion secondary batteries application.LiTFSI-Py ${ }_{14}$ TFSI solutions with various concentrations of LiTFSI salt were prepared by dissolving required amount of LiTFSI in neat Py ${ }_{14}$ TFSI. The Py ${ }_{14}$ TFSI/LiTFSI Room Temperature Ionic Liquid (RTIL) system prepared were investigated as electrolyte for lithium ion battery by various electrochemical methods using coin-type cells. Electrochemical cells were assembled with the $\mathrm{Li}\left[\mathrm{Li}_{0.2} \mathrm{Mn}_{0.54} \mathrm{Ni}_{0.13} \mathrm{Co}_{0.13}\right] \mathrm{O}_{2}$ cathode electrodes, metallic lithium foil as anode, Cellgard 2300 as separator and LiTFSI-Py ${ }_{14}$ TFSI as electrolyte. All operations were performed in the Argon-filled glove box. The fabricated IL-Cells with LiTFSI salt concentration higher than $0.4 \mathrm{M}$ showed high initial discharge capacity of ca. $190 \mathrm{mAh} / \mathrm{g}$ when tested at $0.2 \mathrm{C}$ together with good cycling stability and higher than $98 \%$ coulombic efficiencies except for the first cycle. Electrochemical impedance spectra (EIS) technique was used to study the stability of the electrode/IL-electrolyte interface. The impedance response of $\mathrm{Li} / 0.6 \mathrm{M}$ LiTFSI-Py ${ }_{14}$ TFSI/cathode cell at open circuit potential (ca. $3 \mathrm{~V}$ ) during storage was recorded. The data were tested at different storage times, extending to 30 days. The results interpreted from equivalent circuit indicate that the resistance of the IL-cells is relatively high, that is, $10 \sim 20 \Omega$ for electrolyte resistance $\left(\mathrm{R}_{\mathrm{e}}\right)$ and $100 \sim 200 \Omega$ for the SEI and charge transfer resistance $\left(\mathrm{R}_{\mathrm{sei}}+\mathrm{R}_{\mathrm{ct}}\right)$. Considering that the lithium ion migration and charge transfer process of the IL-cell is dependent on the temperature [2], the fluctuation of the resistance values at different storage times could be attributed to the fluctuation of the ambient temperature under which the EIS test was carried out. As the total resistance of the IL-cell is relatively stable even after storing for 30 days, a good stability of the cathode/IL electrolyte interface as well as the $\mathrm{Li} / \mathrm{IL}$ electrolyte interface is indicated and the good electrochemical performance of the IL-cells is attributed to the good stability of the electrode/IL electrolyte interface observed. Studies have been conducted to improve the viscosity of the electrolyte by missing with various organic and inorganic solvent system. Preliminary results obtained will be presented and discussed at the meeting.

Key words: Room Temperature Ionic Liquid, Lithium Ion Secondary Battery, $\mathrm{Py}_{14}$ TFSI, LiTFSI

\section{References:}

[1] Appetecchi, G.B., et al., Electrochim. Acta, 2009, 54: 325.

[2] Chou, S.-L., et al., Chem. Mater., 2008, 20: 7044. 